УДК 336.761

\title{
КОНКУРЕНТНЫЕ ПРЕИМУЩЕСТВА ОРГАНИЗАЦИИ
}

\author{
С.Ф. КУГАН \\ заместитель декана экономического факультета Брестского государственного технического университета, \\ канд. экон. наук, доц., г. Брест
}

\begin{abstract}
Аннотация
Конкурентоспособность организации отражает потенциальные и реальные возможности обеспечивать свои конкурентные преимущества на рынке в условиях постоянно меняющейся внутренней и внешней среды. Изучение потребителей и конкурентов, а также условий конкуренции позволяет организации определить ее преимущества и недостатки перед конкурентами, выработать успешные конкурентные стратегии и поддержать конкурентные преимущества.
\end{abstract}

Abstract
The competitiveness of the organization reflects the potential and real opportunities to ensure their competitive advantage in the market in a constantly changing internal and external environment. A study of consumers and competitors, as well as the conditions of competition allows the organization to identify its strengths and weaknesses to competitors, develop successful competitive strategies and maintain a competitive advantage.

\section{ВВЕДЕНИЕ}

Пути повышения конкурентоспособности организаций в условиях современного рынка определяются повышением качества продукции, снижением цен на работы и услуги, внедрением инновационных технологических процессов, поиском новых возможностей в направлении снижения затратных механизмов, внедрения ресурсо- и энергосберегающих технологий, сокращения импортной составляющей в структуре себестоимости, расширения выпуска импортозамещающей продукции.

Современные исследователи помимо двух основных типов конкурентных преимуществ (низких затрат и дифференциации) добавляют целый ряд новых, в том числе маркетинговый; управленческий; правовой и др. Но при этом, большинство однозначно определяют цену и качество, как основополагающие конкурентные преимущества. Другими словами, конкурентоспособность означает способность организации прибыльно производить и реализовывать продукцию по цене не выше и по качеству не хуже, а порой и лучше, чем у других предприятий. При этом необходимо рассматривать все факторы, влияющие на повышение конкурентоспособности организаций, предварительно сгруппировав их по функциональной направленности.

Рассматривая организацию как экономическую систему необходимо отметить тот факт, что общая конкурентоспособность организации представляется как сумма конкурентоспособностей составных частей системы. Сама же конкурентоспособность как экономическая категория, предполагает необходимость комплексного рассмотрения и классификации критериев и параметров, определяющих конкурентоспособность всех составных элементов экономической системы. Решение задачи с точки зрения комплексного определения конкурентоспособности, в свою очередь, позволит объективно оценивать и выделять границы конкурентоспособности объектов и субъектов хозяйствования как на макро-, так и на микроуровне [1].

\section{РЕЗУЛЬТАТЫ И ИХ ОБСУЖДЕНИЕ}

Прежде чем говорить о конкурентоспособности, необходимо определить, что является ее основой, что явилось началом и без чего самого понятия не могло быть. Конкуренция - соперничество между хозяйствующими субъектами за ограниченные ресурсы (материальные, финансовые, человеческие и т.д.), посредством поиска оптимальных методов решения существующих задач, которые, в конечном итоге, служат интересам всего общества и стимулируют переход экономической системы на новый этап развития. Данная трактовка конкуренции базируется на учете современных тенденций в понимании этого понятия, объединяя подходы к конкуренции, с одной стороны, как к борьбе, с другой, как к стимулу, который является залогом развития общества и вывода экономической системы на новый этап развития.

Конкурентоспособность, как и конкуренция, имеет неоднозначное толкование в отечественной и зарубежной литературе [2]. Исходя из проведенного анализа определений понятия «конкурентоспособность», были выявлены признаки, раскрывающие сущность данной категории:

1. Конкурентоспособность проявляется и существует только в условиях рынка.

2. Понятие «конкурентоспособность» многовариантно, при этом обладает свойством универсальности и распространяется как на объект (товар, услуга), так и на субъект (организация, отрасль, страна в целом) рыночных отношений.

3. Конкурентоспособность обладает многоуровневостью (товарный, микро-, мезо- и макроуровень), на каждом из которых используется свой набор характеристик для определения конкурентоспособности.

4. Конкурентоспособность - динамичная категория, что обусловлено неустойчивостью отношений на рынке. 
5. Конкурентоспособность - относительная величина, где базой для сравнения выступают аналогичные показатели конкурентов.

Принимая во внимание уже существующие определения конкурентоспособности организации и их недостатки, отметим, что данная категория должна отражать следующие позиции:

- понятия конкурентоспособность продукции и производственной организации тесно взаимосвязаны, так как зачастую конкурентоспособность товаров предопределяет конкурентоспособность всей организации. Вместе с тем, их нельзя отождествлять, потому, что конкурентоспособность организации определяется дополнительными характеристиками, отличными от используемых при определении конкурентоспособности продукции;

- конкурентоспособность организации - относительная категория, поэтому необходимо оговаривать базу сравнения, для получения наиболее объективных результатов;

- конкурентоспособность организации - величина непостоянная и должна отражать возможности предприятия адаптироваться к постоянно меняющимся условиям внешней и внутренней среды;

- конкурентоспособность организации - сложный комплексный показатель и ее оценку нельзя свести к определению одного показателя.

Исходя из выше сказанного, соединив все присущие данному понятию признаки, можно утверждать, что конкурентоспособность организации - это ее комплексная характеристика, отражающая потенциальные и реальные возможности организации обеспечивать свои конкурентные преимущества на рынке в условиях постоянно меняющейся внутренней и внешней среды [3].

Еще одной проблемой в вопросе характеристики организации является отсутствие на сегодняшний день общепринятого подхода к классификации факторов конкурентоспособности. При определении факторов конкурентоспособности организации необходимо учитывать специфику отрасли и особенности внешней среды. В настоящее время на первый план выходят неценовые факторы конкурентоспособности, из которых важнейшее значение приобретают: имидж организации, качество и новизна выпускаемой им продукции, узнаваемость брэнда. В связи с ускорением научно-технического прогресса инновативность предприятия становится одним из основополагающих факторов его конкурентоспособности. В последнее время возрастает значение экологического фактора. Это обусловлено появлением более жестких экологические стандартов, предъявлемых как к производственному процессу, так и к выпускаемой продукции. Постоянно возрастающие требования к качеству товара и одновременно острая конкуренция на рынке заставляют производственные организации при разработке новых изделий использовать принципы экологической безопасности. Кроме того цены на товары и услуги должны учитывать затраты на производство и дальнейшую утилизацию отходов. Так как конкурентоспособность организации категория динамическая, то при классификации и анализе ее факторов (конкурентных преимуществ) необходимо принимать во внимание не только реальное состояние внешней и внутренней среды, но и потенциальные возможности организации. Очевидно, что чем шире у организации набор конкурентных преимуществ, тем более благоприятные предпосылки она имеет для успешной деятельности как на внутреннем, так и на внешнем рынках, что в конечном итоге отражается на конкурентоспособности не только отрасли, но и всей национальной экономики [4]. Автором была обобщена и дополнена система внешних факторов, оказывающих влияние на устойчивое развитие и конкурентоспособность организации:

1. Финансовые:

1.1 рост объема национального дохода;

1.2 снижение уровня инфляции;

1.3 ускорение платежного оборота;

1.4 стабильность налоговой системы.

2. Социальные:

2.1 рост реальных доходов населения;

2.2 снижение уровня безработицы.

3. Рыночные:

3.1 увеличение емкости внутреннего рынка;

3.2 рост активности фондового рынка;

3.3 стабильность валютного рынка.

4. Прочие:

4.1 политическая стабильность;

4.2 демографическая ситуация;

4.3 благоприятные условия для ведения предпринимательской деятельности.

Помимо внешних факторов, на конкурентоспособность организации влияет целая группа внутренних факторов, составляющих конкурентное преимущество организации (таблица 1). 
Таблица 1 - Внутренние факторы конкурентных преимуществ организации

\begin{tabular}{|c|c|c|}
\hline Фактор & Действия & Ответственный \\
\hline \multicolumn{3}{|l|}{ Структурные факторы: } \\
\hline Миссия организации & $\begin{array}{ll}\text { 1. } & \text { Оригинальная идея. } \\
\text { 2. } & \text { Эксклюзивная сфера деятельности. } \\
\text { 3. } & \text { Популярная товарная марка. } \\
\text { 4. } & \text { Бренд. } \\
\text { 5. } & \text { Конкурентоспособная продукция. }\end{array}$ & $\begin{array}{l}\text { Руководитель, отдел марке- } \\
\text { тинга. }\end{array}$ \\
\hline $\begin{array}{l}\text { Организационная структура орга- } \\
\text { низации }\end{array}$ & $\begin{array}{l}\text { Дерево целей с горизонтальной координацией } \\
\text { всех работ (проблемно-целевая организацион- } \\
\text { ная структура) }\end{array}$ & $\begin{array}{l}\text { Начальники отделов, участ- } \\
\text { ков }\end{array}$ \\
\hline $\begin{array}{l}\text { Специализация } \\
\text { производства }\end{array}$ & Рационализация структур и процессов & Руководитель, замы \\
\hline $\begin{array}{l}\text { Уровень унификации и стандар- } \\
\text { тизации выпускаемой продукции } \\
\text { и составных частей производства }\end{array}$ & $\begin{array}{l}\text { 1. Стандартизация всех процессов и проце- } \\
\text { дур производства. } \\
\text { 2. Упорядочение всех видов работ по груп- } \\
\text { пам, методам. }\end{array}$ & $\begin{array}{l}\text { Начальники отделов, участ- } \\
\text { ков, бригадиры. }\end{array}$ \\
\hline $\begin{array}{l}\text { Учет и регулирование производ- } \\
\text { ственных процессов }\end{array}$ & $\begin{array}{l}\text { 1. Мониторинг протекания отдельных про- } \\
\text { цессов. } \\
2 \text {. Возможность оценки ритмичности произ- } \\
\text { водственных процессов, их последовательно- } \\
\text { сти или параллельности. }\end{array}$ & $\begin{array}{l}\text { Руководитель, начальники } \\
\text { отделов, участков, бригади- } \\
\text { ры. }\end{array}$ \\
\hline Персонал организации & $\begin{array}{ll}\text { 1. } & \text { Отбор персонала. } \\
\text { 2. } & \text { Повышение квалификации. } \\
\text { 3. } & \text { Мотивация. } \\
\text { 4. } & \text { Стимулирование }\end{array}$ & Руководитель, отдел кадров. \\
\hline $\begin{array}{l}\text { Информационная и нормативно- } \\
\text { методическая база управления }\end{array}$ & $\begin{array}{l}\text { 1. Соответствие } \text { нормативно-методических } \\
\text { документов СМК. } \\
\text { 2. Соответствие } \\
\text { документов отраслевым стандартам. }\end{array}$ & $\begin{array}{l}\text { Руководитель, отдел каче- } \\
\text { ства. }\end{array}$ \\
\hline \multicolumn{3}{|l|}{ Ресурсные факторы: } \\
\hline Сырье & $\begin{array}{l}\text { 1. Мониторинг рынка на возможность до- } \\
\text { ступа к качественному и дешевому сырью. } \\
\text { 2. Рассмотрение вариантов долгосрочных } \\
\text { поставок. } \\
\text { 3. Различные варианты финансовых расче- } \\
\text { тов. }\end{array}$ & $\begin{array}{l}\text { Руководитель, отдел снаб- } \\
\text { жения, финансовый отдел. }\end{array}$ \\
\hline Поставщики & $\begin{array}{l}\text { 1. } \text { Анализ внешней среды. } \\
\text { 2. Оценка поставщиков. } \\
\text { 3. } \\
\text { Выбор лучших. }\end{array}$ & $\begin{array}{l}\text { Отдел снабжения, марке- } \\
\text { тинговый отдел. }\end{array}$ \\
\hline $\begin{array}{l}\text { Учет и анализ использования всех } \\
\text { видов ресурсов по всем стадиям } \\
\text { жизненного цикла продукции }\end{array}$ & $\begin{array}{l}\text { 1. Мониторинг запасов. } \\
\text { 2. Внедрение ресурсосберегающих техноло- } \\
\text { гий. } \\
\text { 3. Автоматизация отдельных участков про- } \\
\text { изводства. } \\
\text { 4. Оптимизация эффективности использова- } \\
\text { ния ресурсов. }\end{array}$ & $\begin{array}{l}\text { Руководитель, начальники } \\
\text { цехов, участков, бригадиры. }\end{array}$ \\
\hline $\begin{array}{l}\text { Функционально-стоимостной ана- } \\
\text { лиз выпускаемой продукции и } \\
\text { элементов производства }\end{array}$ & $\begin{array}{l}\text { Проведение } \quad \text { функционально-стоимостного } \\
\text { анализа }\end{array}$ & Экономический отдел \\
\hline \multicolumn{3}{|l|}{ Технические факторы: } \\
\hline Оборудование & $\begin{array}{l}\text { 1. Обновление и модернизация оборудова- } \\
\text { ния. Увеличение удельного веса современного } \\
\text { технологического оборудования. } \\
2 . \text { Снижение среднего возраста технологиче- } \\
\text { ского оборудования. }\end{array}$ & $\begin{array}{l}\text { Отдел главного инженера, } \\
\text { отдел главного технолога, } \\
\text { финансовый отдел }\end{array}$ \\
\hline Технологии & $\begin{array}{l}\text { Увеличивать количество патентованных тех- } \\
\text { нологий }\end{array}$ & Отдел главного технолога \\
\hline Товар & Выпуск сертифицированного товара & Производственный отдел \\
\hline Качество продукции & $\begin{array}{l}\text { Применение современных методов контроля и } \\
\text { стимулирования качества }\end{array}$ & $\begin{array}{l}\text { Производственный } \\
\text { отдел качества }\end{array}$ \\
\hline
\end{tabular}




\begin{tabular}{|c|c|c|}
\hline \multicolumn{3}{|l|}{ Управленческие факторы: } \\
\hline $\begin{array}{l}\text { Функционирование системы ме- } \\
\text { неджмента качества }\end{array}$ & Разработать и внедрить & $\begin{array}{l}\text { Руководитель, отдел каче- } \\
\text { ства }\end{array}$ \\
\hline $\begin{array}{l}\text { Функционирование } \quad \text { системы } \\
\text { управления качеством в организа- } \\
\text { ции }\end{array}$ & $\begin{array}{l}\text { 1.Разработка и внедрение системы. } \\
\text { 2. Соответствие системы управления каче- } \\
\text { ством международным стандартам. }\end{array}$ & $\begin{array}{l}\text { Руководитель, отдел каче- } \\
\text { ства }\end{array}$ \\
\hline $\begin{array}{l}\text { Организация поставок сырья, ма- } \\
\text { териалов, комплектующих изде- } \\
\text { лий в соответствие с концепцией } \\
\text { «точно в срок» }\end{array}$ & Дисциплина поставок. & $\begin{array}{l}\text { Руководитель, отдел снаб- } \\
\text { жения. }\end{array}$ \\
\hline \multicolumn{3}{|l|}{ Рыночные факторы: } \\
\hline Доступ к рынку ресурсов & $\begin{array}{l}\text { Проведение мониторинга рыночной инфра- } \\
\text { структуры }\end{array}$ & $\begin{array}{l}\text { Руководитель, отдел снаб- } \\
\text { жения, отдел маркетинга }\end{array}$ \\
\hline Доступ к рынку новых технологий & $\begin{array}{l}\text { Проведение мониторинга рыночной инфра- } \\
\text { структуры }\end{array}$ & $\begin{array}{l}\text { Руководитель, отдел снаб- } \\
\text { жения, отдел маркетинга }\end{array}$ \\
\hline Эксклюзивность продукции & Высокая патентоспособность & $\begin{array}{l}\text { Руководитель, отдел каче- } \\
\text { ства. }\end{array}$ \\
\hline $\begin{array}{l}\text { Эксклюзивность каналов распре- } \\
\text { деления }\end{array}$ & Высокий уровень логистики & $\begin{array}{l}\text { Отдел маркетинга, отдел } \\
\text { сбыта. }\end{array}$ \\
\hline $\begin{array}{l}\text { Эксклюзивность рекламы продук- } \\
\text { ции организации }\end{array}$ & $\begin{array}{l}\text { 1. Высокая квалификация сотрудников отде- } \\
\text { ла рекламы. } \\
\text { 2. Достаточные средства }\end{array}$ & $\begin{array}{l}\text { Отдел маркетинга, отдел } \\
\text { рекламы, отдел сбыта. }\end{array}$ \\
\hline $\begin{array}{l}\text { Эффективная системы сбыта и } \\
\text { послепродажного обслуживания }\end{array}$ & $\begin{array}{l}\text { 1. Высокая квалификация экономистов, пси- } \\
\text { хологов, менеджеров. } \\
\text { 2. Достаточные средства. }\end{array}$ & $\begin{array}{l}\text { Отдел маркетинга, отдел } \\
\text { рекламы, отдел сбыта. }\end{array}$ \\
\hline $\begin{array}{l}\text { Прогнозирование политики цено- } \\
\text { образования и рыночной инфра- } \\
\text { структуры }\end{array}$ & $\begin{array}{l}\text { 1. Анализ спроса и предложения по всем } \\
\text { товарам. } \\
\text { 2. Организация качественной информаци- } \\
\text { онной базы. } \\
\text { 3. Квалифицированные специалисты. }\end{array}$ & $\begin{array}{l}\text { Отдел маркетинга, отдел } \\
\text { рекламы, отдел сбыта, эко- } \\
\text { номический отдел }\end{array}$ \\
\hline \multicolumn{3}{|c|}{ Эффективность функционирования организации: } \\
\hline Оценка показателей доходности & $\begin{array}{ll}\text { 1. } & \text { Рентабельность продукции. } \\
\text { 2. } & \text { Рентабельность производства. } \\
\text { 3. } & \text { Рентабельность капитала. } \\
\text { 4. } & \text { Рентабельность продаж. }\end{array}$ & Экономический отдел \\
\hline $\begin{array}{l}\text { Интенсивность } \\
\text { капитала }\end{array}$ & $\begin{array}{l}\text { 1. Коэффициент оборачиваемости видов } \\
\text { peсурсов. } \\
2 . \quad \text { Коэффициент оборачиваемости капита- } \\
\text { ла. }\end{array}$ & Экономический отдел \\
\hline
\end{tabular}

Р.А. Фатхутдинов рассматривал конкуренцию как процесс мониторинга, позволяющий управлять конкурентными преимуществами, слабостями и внешними угрозами в адрес как субъекта, так и его конкурента по достижению одной и той же цели [5]. По его мнению, уровень рыночной устойчивости организации формируется под непосредственным влиянием факторов внешней и внутренней среды и определяется, как способность организации достигать целей своего развития в соответствии с имеющимся в наличии ресурсным обеспечением и требованиями рынка. Им были сформированы основные принципы управления конкурентоспособностью организации:

1) анализ механизмов действий экономических законов и законов организации (закон конкуренции, закон спроса, закон возрастания дополнительных затрат, закон обратной связи и др.);

2) соблюдение научных подходов и принципов;

3) применение современных подходов и принципов;

4) ориентация на количественные методы управления;

5) взвешивание показателей конкурентоспособностей;

6) применение относительных и удельных показателей;

7) исключение из состава показателей конкурентоспособности объектов показателей эффективности и качества управления, так как первые являются результатом, а вторые - условием достижения конкурентоспособности;

8) принятие в качестве первой общей функции управления стратегического менеджмента.

Конкурентоспособность организации напрямую зависит от уровня ее устойчивости и определяется результативностью реализации не только текущих заданий, но и долгосрочных программ развития, а также требует принципиально новых подходов к управлению конкурентоспособностью организации с целью ее повышения.

Изучение потребителей и конкурентов, а также условий конкуренции позволяет организации определить ее преимущества и недостатки перед конкурентами, выработать успешные конкурентные стратегии и поддержать конкурентные преимущества. Организация должна знать, в какой степени она конкурентоспособна по отношению к другим 
субъектам данного рынка, так как высокая степень конкурентоспособности является гарантом получения высоких экономических показателей в рыночных условиях, и иметь стратегической целью достижения такого ее уровня, который помог бы ей выживать в условиях жесткой конкурентной борьбы.

Формирование высокого уровня конкурентоспособности организации зависит не только от ее потенциальных возможностей, условий реализации стратегических направлений развития и разрешения проблем оптимального использования ресурсного обеспечения, но и от использования эффективных концепций управления самой конкурентоспособностью.

Как известно, конкурентоспособность организации представляет собой сложную экономическую категорию. На основе проведенного анализа имеющейся экономической литературы по проблеме конкурентоспособности организации выделено три основных ее характеристики.

Это, во-первых, адаптивность организации к изменениям окружающей среды; во-вторых, конкурентные преимущества в рамках комплекса маркетинга; в-третьих, результаты экономической деятельности (относительно конкурентов). Таким образом, к конкурентоспособности организации нужно подходить как к многомерной концепции и для ее измерения необходимо использовать специальные переменные адаптивности, конкурентных преимуществ и результатов экономической деятельности. Из сказанного следует, что одно из важных направлений управления конкурентоспособностью организации состоит в разработке методов повышения ее конкурентных преимуществ и адаптационных свойств.

По мнению автора, изучение конкурентоспособности и уровня ее управления необходимо проводить, учитывая фазы и этапы развития организации. В условиях перехода организации из одной фазы развития её жизненного цикла в другую, возникает необходимость определить и реализовать условия рационального управления организацией, усиливающие (увеличивающие) показатели ее устойчивости и качества динамических характеристик развития процессов управления. В этих условиях появляется потребность в определении действий, поддерживающих положительный баланс устойчивости процессов управления. Определяются временные границы воздействия этих сил на стабилизацию процессов управления, что и является одной из главных задач перехода системы управления организацией из одной фазы в другую.

Процедура перехода системы управления организацией из одной фазы развития её жизненного цикла в другую является динамическим процессом, следовательно, будет меняться в процессе перехода.

Уровень управляемости (УУ) - представляет собой интегральный показатель эффективности процесса управления, характеризующий и оценивающий состояние системы как целого, интегрируя управленческие, экономические, организационные и социальные аспекты управления на конкретный момент времени.

Конкурентоспособность продукции (КС) - это совокупность потребительских свойств товара, отражающая его отличие от аналогов других производителей по степени соответствия потребительским потребностям качества (К) и цены (Ц). Эффективность инновационных технологий (ЭИТ) определяется приращением $(\Delta)$ уровней управляемости и конкурентоспособности в новых условиях функционирования производственной организации, т.е.:

ЭИТ(t) = f(УУ( $\left.\mathrm{t}^{\text {ИТ }}\right) ;$ КС(Ц; К; $\left.\left.\mathrm{t}^{\text {ИТ }}\right)\right)$,

Где Ц - цена товара;

К - качество;

$\mathrm{t}^{\text {ИT }}$ - время реализации инновационной технологии.

Рассмотренная математическая зависимость эффективности позволяет ввести показатели оценки инновационных технологий и определять (в зависимости от величины ЭИТ) объем инноваций, требуемый для удержания организации в устойчивом режиме работы [6].

\section{ВЫВОДЫ}

Конкурентное преимущество организации может быть признано стратегическим конкурентным преимуществом, если оно является глобальным, т.е. устойчиво во времени и привлекает широкое и постоянное внимание со стороны внешнего окружения предприятия. Показателем, характеризующим результат стратегического управления, является показатель стратегического успеха или неуспеха деятельности организации на рынке (рост или падение его рыночной доли). Тактическое управление конкурентоспособностью направлено на формирование тактики обеспечения конкурентоспособности - совокупности видов, приемов и методов конкурентной борьбы, которые избирает и практически применяет организация против своих конкурентов и с помощью которых она реализует свою конкурентную стратегию. Показателем тактического управления будет являться совокупность результатов, характеризующих достигнутый уровень в формировании, поддержании или развитии стратегического конкурентного преимущества за тактический конкурентный период. Тогда под тактическим конкурентным преимуществом будем понимать конкурентное преимущество, вызывающее хоть и ограниченное, но растущее внимание со стороны внешнего окружения организации, приобретающее устойчивость во времени и в отношении которого у конкурентов отсутствуют очевидные возможности его «нейтрализации». Текущее управление осуществляется в процессе решения текущих задач обеспечения конкурентоспособности организации. Кроме того, текущее (оперативное) управление конкурентоспособностью должно предполагать проведение конкурентного маневрирования, представляющего собой комплекс мер, разрабатываемых и осуществляемых для устранения не предусмотренных ранее ситуаций. Тактический и оперативный 
(текущий) уровни управления конкурентоспособностью предприятия осуществляются всеми субъектами управления с основным упором на среднее и нижнее звенья управления. Акцент делается на среднесрочные (период от одного года до трех лет) и краткосрочные (до одного года) периоды. Система управления конкурентоспособностью организации основывается на процессах управления, каждый из которых может быть оценен и измерен в трех временных интервалах (стратегическом, текущем и оперативном).

\section{ЛИТЕРАТУРА}

1.Высоцкий, О.А. Диагностика и мониторинг процессов управления хозяйственными системами / О.А. Высоцкий ; Центр. науч.-исслед. и проект. технолог. ин-т орг. и техники упр. - Минск : ЦНИИТУ, $1999 .-240$ с.

2. Миротин Л.Б., Ташбаев И.Э. Снабженческая логистика / Л.Б. Миротин, И.Э. Ташбаев. - М.: Инфра-М, 2009. $326 \mathrm{c}$.

3. Родионова В.Н. Оптимизация материальных потоков в производственно-сбытовой системе / В.Н. Родионова, Н.В. Федоркова. - Воронеж: ВТГУ, 2009. - 369 с.

4. Фатхудинов, Р.А. Производственный менеджмент : учеб. для вузов / Р.А. Фатхудинов. - 2-е изд., доп. - М. : БИзнес-шк. «ИНТЕЛ-СИНТЕЗ», 2008. - 195 с.

5. Фатхудинов, Р.А. Управление конкурентоспособностью организации / Р.А. Фатхутдинов. - 3-е изд., перераб. и доп. - М.: Маркет ДС, 2008. - 432 с.

6. Высоцкий, О.А. Теория измерения управляемости хозяйственной деятельностью предприятия / О.А. Высоцкий. - Минск : Право и экономика, 2004. - 396 с.

Статья поступила в редакияию 8 июня 2015 года. 